\title{
Determinación in vitro del efecto antibacteriano de la miel de la abeja común (Apis mellífera) y de la abeja angelita (Tetragonisca angustula) ante el Staphylococcus aureus coagulasa positivo
}

In vitro determination of the antibacterial effect of honey bee (Apis mellifera) and little angel bee (Tetragonisca angustula) against positive coagulase Staphylococcus aureus

\author{
Romero Rojas Yenny ${ }^{1}$ y Gómez Leal Luz Adiela² \\ ${ }^{1}$ Medico Veterinario Zootecnista. Universidad de los Llanos \\ ${ }^{2}$ Bacteriologa Esp. Docente Universidad de los Llanos \\ luz.gomez.leal@unillanos.edu.co
}

Recibido 05 de Marzo 2013, Aceptado 15 de Abril 2013

\section{RESUMEN}

El uso indebido e indiscriminado de los antibióticos en las últimas décadas, para profilaxis de enfermedades tanto en el hombre como en los animales, ha detonado una alarma en el mundo de la medicina microbiológica, ya que dichos microorganismos han respondido de una manera peligrosa, con la llamada resistencia bacteriana, por eso es necesario reconocer, investigar y aplicar en nuestro campo profesional, las opciones alternas que existen en medicina veterinaria. Los objetivos comprendidos en el presente estudio son los de establecer si la miel de la abeja Apis mellífera (abeja común de la miel) y la miel de la Tetragonisca angustula (abeja angelita o virgencita) obtenidas de nuestra flora regional, poseen alguna característica antibacteriana que logre inhibir el desarrollo microbiano en las diferentes concentraciones bacteriales de siembra, para posteriormente analizarlos y compararlos entre sí estadísticamente. A los resultados obtenidos se les hizo un análisis comparativo y descriptivo de la media poblacional, utilizando para esto el programa Software estad.graphad.instat versión 3.06 (2003). Se buscó las diferencias entre parejas estadísticamente significativas $\mathrm{P}<0.005$ aplicando la prueba de rangos múltiples o Test de TukeyKramer. Las mieles puras tanto de la Apis mellifera como de la Tetragonisca angustula presentaron la mayor inhibición en concentraciones bacterianas in vitro 
de $1 \times 10^{-4}$ UFC. Las mieles diluidas de la Apis mellifera y Tetragonisca angustula al $20 \%$ no presentaron suficiente inhibición ante las concentraciones de $1 \times 10^{-1}, 1 \times 10^{-2}$ y $1 \times 10^{-3}$ UFC. El resto de las diluciones no presentaron una diferencia marcada entre sí por lo que se consideraron en general inhibitorias para las cuatro concentraciones. Todas las mieles estuvieron dentro de un rango de $21.2 \mathrm{~mm}$ como máximo y $11 \mathrm{~mm}$ como diámetro mínimo; el máximo obtenido, correspondió a la miel pura de la abeja Apis mellifera ante la concentración de $1 \times 10^{-4}$ UFC y el mínimo correspondió a la miel de la Tetragonisca angustula en dilución al 20\% ante la concentración bacteriana de $1 \times 10^{-1}$ UFC. En todos sus estados la miel fue superior al control positivo: oxitetraciclina al 10\%. En conclusión, se comprobó durante este estudio que la miel de la abeja Apis mellífera y de la Tetragonisca angustula, puras y diluidas al 50 y $20 \%$, poseen propiedades antibacteriales que las hacen efectivas para detener el crecimiento de las colonias del Staphylococcus aureus coagulasa positivo, en un ensayo in vitro y que las concentraciones mínimas inhibitorias de la miel dependen de la concentración bacteriana y del estado puro o diluido de las mismas mieles. Se podría recomendar que, para próximos estudios de esta índole, sea necesario establecer antes, la presencia y cantidad de las enzimas catalasa y glucoxidasa en la miel sometida a estudio; además de obtener el porcentaje de humedad específico para la misma.

Palabras clave: Resistencia bacteriana, antibacteriano, concentración mínima inhibitoria, miel.

\section{ABSTRACT}

The indiscriminate misuse of antibiotics in recent decades, for prophylaxis of diseases in man and animals, has triggered an alarm in the world of medicine microbiological, since these microorganisms have responded in a dangerous way, with called bacterial resistance, so it is necessary to recognize, investigate and apply in our professional field, there are alternative options in veterinary medicine. The objectives in the present study are to establish if the honey bee Apis mellifera (honeybee) and honey bee Tetragonisca angustula (angelita or virgin bee) obtained from our regional flora, possess some antibacterial feature inhibit 
microbial growth achieved in different bacterial concentrations planting, later analyze and compare them statistically. The results obtained were asked comparative and descriptive analysis of the population mean, using this program estad.graphad.instat Software version 3.06 (2003). It looked for statistically significant differences between pairs $\mathrm{P}<0.005$ using multiple range test or TukeyKramer test. Pure honeys both Apis mellifera and the Tetragonisca angustula showed the highest inhibition in vitro bacterial concentrations $1 \times 10^{-4}$ UFC. The diluted honey of Apis mellifera and Tetragonisca angustula 20\% did not present sufficient inhibition at concentrations of $1 \times 10^{-1}, 1 \times 10^{-2}$ and $1 \times 10^{-3}$ UFC. The remaining dilutions showed no marked difference from each other by what is generally considered to four inhibitory concentrations. All honeys were within a range of $21.2 \mathrm{~mm}$ and maximum diameter of $11 \mathrm{~mm}$ as minimum, maximum obtained corresponded to pure honey bee Apis mellifera to the concentration of $1 \times 10^{-4} \mathrm{CFU}$ and the minimum corresponded to honey the Tetragonisca angustula in dilution to $20 \%$ at the concentration of $1 \times 10^{-1}$ bacterial CFU. In all states honey was superior to the positive control: oxytetracycline $10 \%$. In conclusion it was found during this study that the honey bee Apis mellifera and Tetragonisca angustula, pure and diluted to 50 and $20 \%$, possess antibacterial properties that make them effective in stopping the growth of colonies of coagulase-positive Staphylococcus aureus, in an in vitro assay and minimum inhibitory concentrations of honey depend on bacterial concentration and pure or dilute them honeys. It could recommend that future studies of this nature are required before the presence and quantity of the catalase and glucosidase enzymes in honey under study, besides obtaining the specific moisture for it.

Keywords: Bacterial resistance, antibacterial, minimum inhibitory concentration, honey.

\section{INTRODUCCIÓN}

La miel es un producto de la colmena, elaborado por las abejas, en especial por la abeja melífera común, otros productos son: el polen, propóleo, jalea real, cera y apitoxina. Específicamente a la miel se le han reconocido propiedades medicinales 
desde la antigüedad; como tratamiento terapéutico contra infecciones causadas por bacterias y hongos, en heridas abiertas, ulceras, quemaduras e infecciones oculares. Gracias a la historia y la arqueología se han hallado y corroborado hechos remotos del hombre de la edad de bronce, los cuales ejercían una medicina primitiva como se prueba en los cráneos encontrados con marcas de trepanación y en cuyo interior se evidencian restos de propóleo, producto al cual se le atribuyen actualmente propiedades antisépticas (Engel, 1998; PROFECO, 2001).

Los egipcios, chinos, persas, hindú, griegos y romanos (pueblos representativos de las civilizaciones clásicas) dejaron innumerables registros del consumo y el uso medicinal de los productos de la colmena. En Egipto las referencias indican el uso del propóleo ante diferentes afecciones y principalmente en el proceso de momificación de los faraones. Estas civilizaciones avanzadas, ubicadas a la orilla del río Nilo, contaban con unos 900 remedios en su medicina tradicional, de los cuales cerca de 500 eran hechos a base de miel de abejas, como dejaron constancia en el papiro de Ebers (3.500 a. C) y en el papiro de Beck Badog (Crane y Graham, 1985; Ulloa et al., 2010). En los textos bíblicos vemos por ejemplo la temprana vocación que tenían los pueblos medio orientales hacia la apicultura, en especial el pueblo Israelita. En la India el Yadaur Veda, considerado el libro más antiguo de medicina en el código Manu, aseguraba que la posibilidad de longevidad era real, si se consumía todos los días pan de abejas (panales frescos de miel con polen).

El padre de la medicina Hipócrates recomendaba el uso de la miel para prolongar la vida, dejando constancia de ello, ya que este galeno griego consumió los productos de la colmena y vivió hasta los 107 años. Un dato anecdótico registrado en la historia, fue el acontecido en Babilonia, cuando murió Alejandro el Grande (Magnus), cuyo cuerpo debía ser sepultado en su ciudad de origen Macedonia, pero como el viaje duraba alrededor de dos meses decidieron sumergirlo en una tina que contenía en su interior miel; así llego su cuerpo a Macedonia sin mostrar ningún signo de descomposición (Crane, 1980; Asis, 2007). 
Diferentes autores han reconocido que las características antibacteriales de la miel se deben en parte a su osmolaridad, su pH, la presencia de peróxido de hidrógeno (Molan, 1992) y algunos componentes fitoquímicos específicos de las diferentes clases de plantas, las cuales le transfieren sus cualidades al néctar recolectado por la abeja.

El presente estudio se inspiró y basó en una entrevista por parte del canal científico: National Geographic, en el año 2003 al doctor Peter Molan, docente de la Universidad de Waikato (Hamilton: Nueva Zelanda) y actual director del laboratorio para estudios de la miel. En un documental se hace referencia al caso de una paciente que sufría una infección cutánea severa en uno de sus antebrazos, causada por el Staphylococcus aureus y cuya acción de los antibióticos incluidos los de última generación, era anulada por dicha bacteria. Pasadas unas pocas semanas de haberse iniciado un tratamiento con miel de abejas, (miel de Manuka) la herida sanó de forma rápida y mostró una adecuada cicatrización.

Los objetivos comprendidos en el presente estudio son los de establecer si la miel de la abeja Apis mellífera (Gráfica 1) (abeja común de la miel) y la miel de la Tetragonisca angustula (Gráfica 2) (abeja angelita o virgencita) obtenidas de nuestra flora regional, poseen alguna característica antibacteriana que logre inhibir el desarrollo microbiano en las diferentes concentraciones bacteriales de siembra, para posteriormente analizarlos y compararlos entre sí estadísticamente (Nates, 1996).

Es fundamental crear y tener conciencia que el uso indebido e indiscriminado de los antibióticos en las últimas décadas, para profilaxis de enfermedades tanto en el hombre como en los animales, ha detonado una alarma en el mundo de la medicina microbiológica, ya que dichos microorganismos han respondido de una manera peligrosa, con la llamada resistencia bacteriana (CEPEC, 2011), por eso es necesario reconocer, investigar y aplicar en nuestro campo profesional, las opciones alternas que existen en medicina veterinaria. 


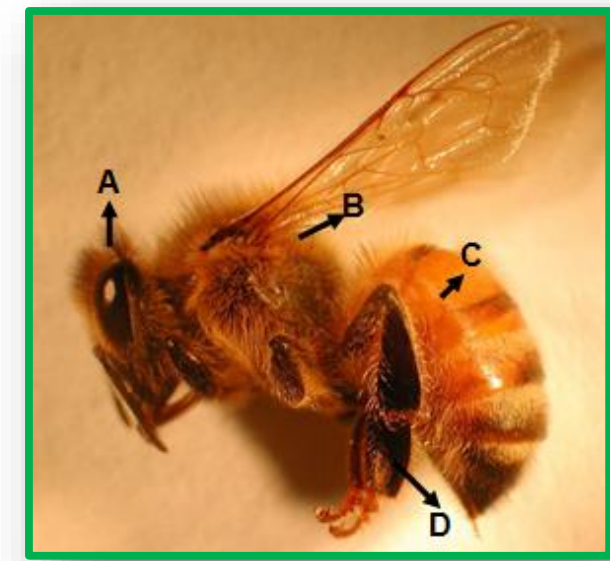

Gráfica 1. Abeja común de la miel mellifera)

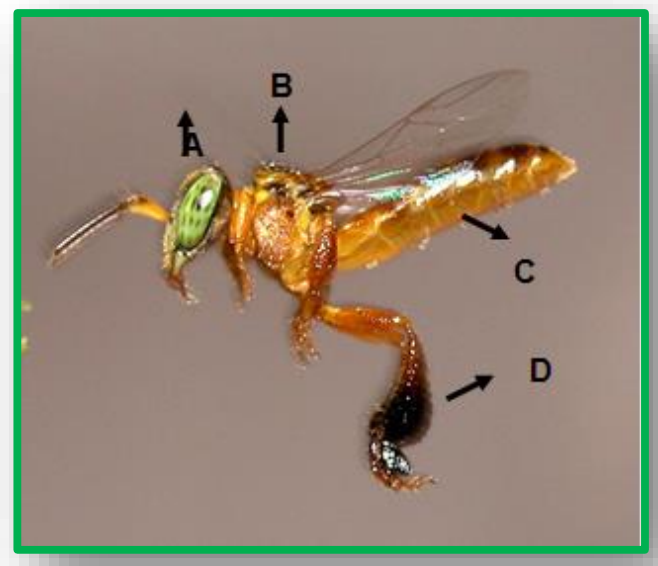

Gráfica 2. Abeja (Tetragonisca (Apis angustula)

(A) Cabeza, (B) tórax, (C) abdomen y (D) cestilla para la recolección del polen

Actualmente se tiene conocimiento de estudios realizados por parte de la Universidad del Tolima, la Universidad Nacional de Bogotá y la Universidad Nacional de Antioquia, acerca de los productos de la colmena, identificación de las razas de abejas y su flora nectaria correspondiente, usos del propóleo, clasificación del polen por zonas y acciones terapéuticas del veneno o apitoxina; sin embargo, no se ha encontrado un registro comparado con el estudio que se efectúa el presente trabajo.

\section{METODOLOGÍA}

Las mieles para este estudio se consideran multiflorales (néctar de origen diverso). La miel de la Apis mellifera provino de la vereda Puerto Colombia y se obtuvo por centrifugación de los panales, en una centrífuga de acero inoxidable con capacidad de cuatro cuadros, fue envasada sin sufrir calentamiento; la miel de la abeja Tetragonisca angustula provino de la vereda Altos de Buena Vista y fue extraída artesanalmente con jeringas estériles y envasada sin sufrir ningún tipo de tratamiento. Se utilizaron para el estudio muestras de miel diluida al 50 y $20 \%(\mathrm{v} / \mathrm{v})$ y miel pura de ambas especies; como diluyente se empleó agua destilada esterilizada (Allen et al., 1991), como control negativo agua estéril y como control positivo oxitetraciclina al $10 \%$. 
La cepa original de Staphylococcus aureus de la cual se obtuvieron las réplicas fue suministrada por el Laboratorio de Microbiología Animal de la Universidad de los Llanos (Gráficas 3 y 4). Después de confirmada la cepa joven con las pruebas de coagulasa y catalasa, se tomó $1 \mathrm{ml}$ de la colonia y se introdujo en el tubo Cero de BHI (infusión cerebro - corazón), de éste se tomó $1 \mathrm{ml}$ y se inoculó el tubo número uno que se rotuló con la concentración de $10^{-1}$; así sucesivamente hasta el tubo seis y el $\mathrm{ml}$ sobrante se descartó (Gráfica 5). Estos cultivos se llevaron a incubar por 4 horas a $37^{\circ} \mathrm{C}$ o hasta detectar turbidez, pero no excediendo las 6 horas. Para determinar la actividad antibacteriana de la miel se empleó la técnica de difusión en agar, en este caso agar selectivo Miüller Hinton, inoculando en el agar para cada concentración, $1 \mathrm{ml}$ de la respectiva colonia desarrollada en los tubos BHI correspondientes (Gráfica 6).

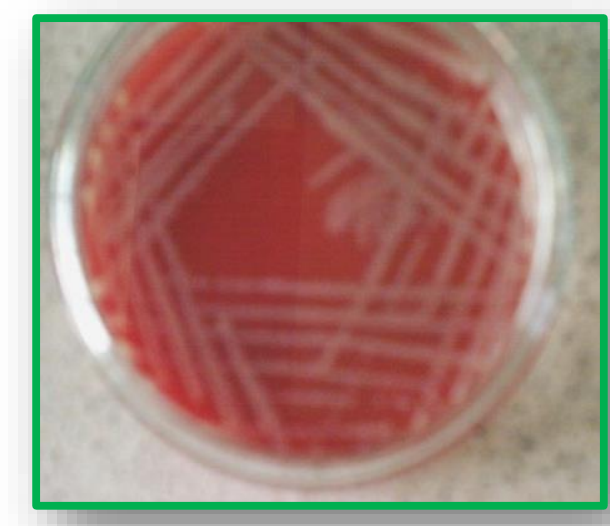

Gráfica 3. Colonias de repique del Staphylococcus aureus en agar sangre

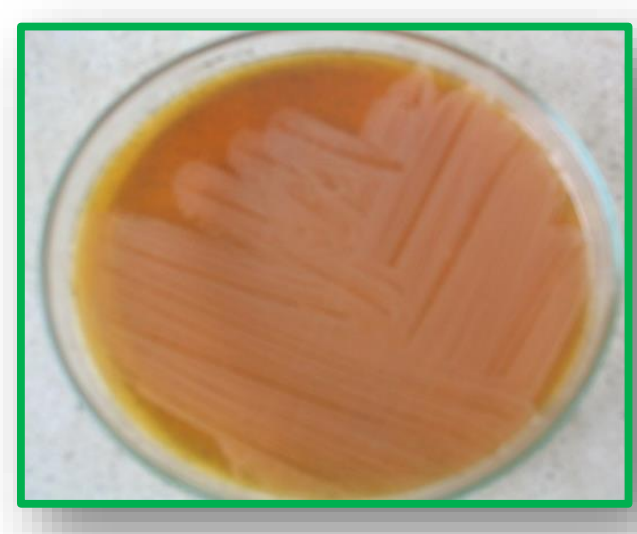

Gráfica 4. Colonias de repique del $S$. aureus en agar salado manita

Una vez vertido y solidificado el agar en las cajas de petri, calculando un grosor de $5 \mathrm{~mm}$ de la capa de agar para cada caja, se hicieron los pozos de $4 \mathrm{~mm}$ de diámetro, dos por caja, agregando $1 \ell$ a cada pozo de la miel pura de ambas especies respectivamente, de igual forma para las cajas con las diluciones al $50 \%$ y al 20\% (Gráfica 7). La medida del pH se realizó con papel indicador (Merck) a las mieles puras, y diluidas de ambas especies. A la caja con los controles se le agregó a los pozos $1 \ell$ de agua estéril (negativo) e igualmente $1 \ell$ de oxitetraciclina 
al 10\% (positivo). Se hicieron cuatro réplicas por concentración, para un total de 96 cajas que se llevaron a incubación por 18 horas a $37^{\circ} \mathrm{C}$.

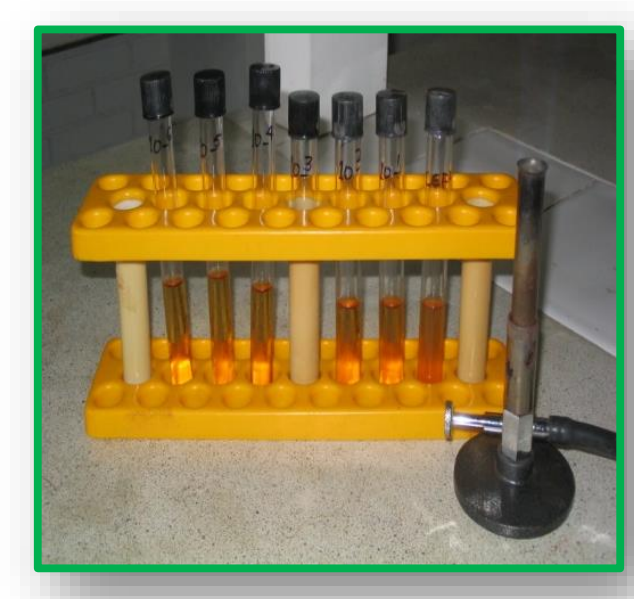

Gráfica 5. Siembra en BHI

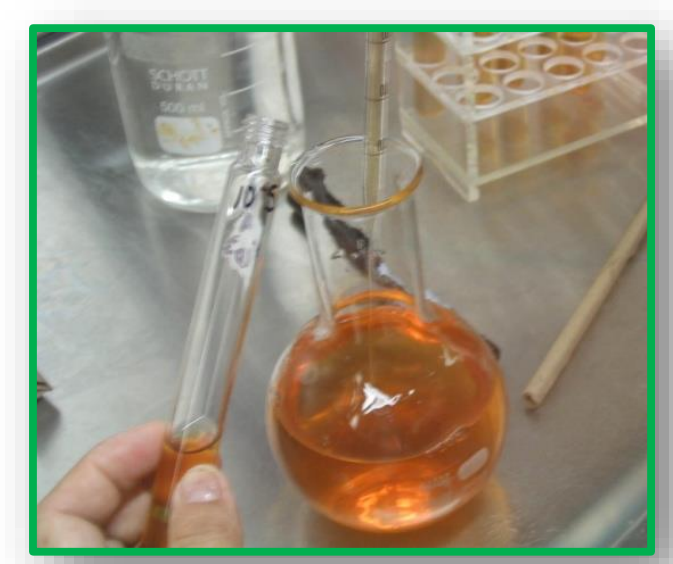

Gráfica 6. Inoculación cepa en el agar

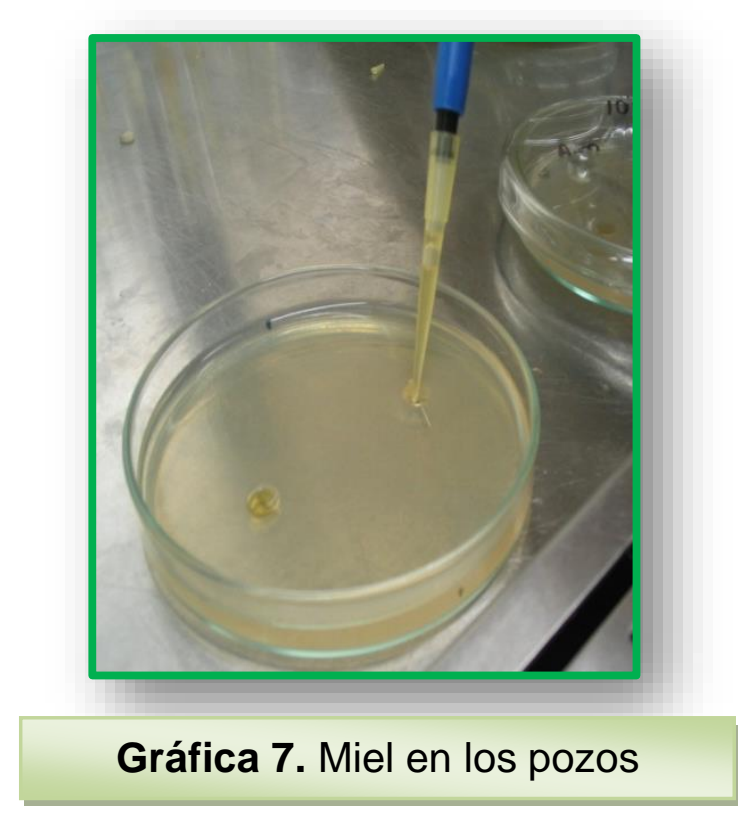

A los resultados obtenidos se les hizo un análisis comparativo y descriptivo de la media poblacional, utilizando para esto el programa Software estad.graphad.instat versión 3.06 (2003). Los datos son expresados +/- Error estándar de la media. Se buscó las diferencias entre parejas estadísticamente significativas $\mathrm{P}<0.005$ aplicando la prueba de rangos múltiples o Test de Tukey-Kramer (Wayne, 2000). 


\section{RESULTADOS Y DISCUSIÓN}

El análisis estadístico y la técnica para el reconocimiento de resistencia bacteriana que expresa en milímetros el diámetro de los halos inhibitorios medidos, arrojaron los siguientes resultados. Según los resultados de la Tabla 1 las mieles puras tanto de la Apis mellifera como de la Tetragonisca angustula presentaron la mayor inhibición en concentraciones bacterianas in vitro de $1 \times 10^{-4}$ UFC. Las mieles diluidas de la Apis mellifera y Tetragonisca angustula al $20 \%$ no presentaron suficiente inhibición ante las concentraciones de $1 \times 10^{-1}, 1 \times 10^{-2}$ y $1 \times 10^{-3}$ UFC. E resto de las diluciones no presentaron una diferencia marcada entre sí por lo que se consideraron en general inhibitorias para las cuatro concentraciones. Todas las mieles estuvieron dentro de un rango de $21.2 \mathrm{~mm}$ como máximo y $11 \mathrm{~mm}$ como diámetro mínimo; el máximo obtenido, correspondió a la miel pura de la abeja Apis mellifera ante la concentración de $1 \times 10^{-4}$ UFC y el mínimo correspondió a la miel de la Tetragonisca angustula en dilución al 20\% ante la concentración bacteriana de $1 \times 10^{-1}$ UFC (Tabla 1 y Figura 1 ).

Este resultado sugiere que la miel de abejas de ambas especies inhibe el crecimiento de la bacteria por la acción del peróxido de hidrogeno, producto de la acción enzimática de la glucoxidasa; esto concuerda con los resultados obtenidos por Molan en 1992, en los que se compara la acción antibacteriana del azúcar artificial y la miel de abejas, los resultados del poder antibacterial por inhibición obtenidos de la miel fueron mayores, a diferencia del azúcar artificial; debido según el autor, a la presencia y cantidad de enzimas que las abejas le agregan a la miel lo que hace más eficiente el peróxido de hidrogeno.

Concuerda también con los estudios hechos por Salazar en el año 2001, donde se evaluó la actividad antibacteriana in vitro de la miel de abejas utilizando cuatro clases de mieles ante el Streptococcus mutans, con los resultados determinaron que las diluciones de la miel al 30 y $35 \%$ (v/v) poseían características antibacteriales que interrumpían el crecimiento de la bacteria por la acción del producto conocido como peróxido de hidrogeno, el cual se presenta como resultado de la oxidación de la glucosa. El rango de dilución que utilizó Salazar se 
encuentra en el rango de las diluciones hechas al 50 y $20 \%(\mathrm{v} / \mathrm{v})$ del presente estudio.

Tabla 1. Concentraciones mínimas inhibitorias (milímetros) de la miel Apis mellifera y la miel de la Tetragonisca angustula en sus presentaciones puras y diluidas al 50 y $20 \%$, frente al Staphylocccus aureus coagulasa positivo.

\section{Concentración Mínima Inhibitoria (Milímetros)}

\begin{tabular}{|c|c|c|c|c|c|}
\hline \multicolumn{2}{|c|}{ Miel Pura } & \multicolumn{2}{|c|}{ Dilución $\mathbf{5 0 \%}$} & \multicolumn{2}{|c|}{ Dilución 20\% } \\
\hline [UFC] ${ }^{\star}$ & (mm) & [UFC] & $(\mathrm{mm})$ & [UFC] & $(\mathrm{mm})$ \\
\hline A.m & 21.2 & $\begin{array}{l}\text { A.m } \\
10^{-4}\end{array}$ & 18.5 & $\begin{array}{l}\text { A.m } \\
10^{-4}\end{array}$ & 16.7 \\
\hline $\begin{array}{c}\text { T.a } \\
10^{-4}\end{array}$ & 20.5 & $\begin{array}{c}\text { T.a } \\
10^{-4}\end{array}$ & 18 & $\begin{array}{c}\text { T.a } \\
10^{-4}\end{array}$ & 16.2 \\
\hline $\begin{array}{l}\text { A.m } \\
10^{-3}\end{array}$ & 19 & $\begin{array}{l}\text { A.m } \\
10^{-}\end{array}$ & 18 & $\begin{array}{l}\text { A.m } \\
10^{-3}\end{array}$ & 13.7 \\
\hline $\begin{array}{l}\text { T.a } \\
10^{-3}\end{array}$ & 18.7 & $\begin{array}{l}\text { T.a } \\
10^{-3}\end{array}$ & 18 & $\begin{array}{l}\text { T.a } \\
10^{-3}\end{array}$ & 12.7 \\
\hline $\begin{array}{l}\text { A.m } \\
10^{-2}\end{array}$ & 17.5 & $\begin{array}{l}\text { A.m } \\
10^{-2}\end{array}$ & 17 & $\begin{array}{l}\text { A.m } \\
10^{-2}\end{array}$ & 12.5 \\
\hline $\begin{array}{c}\text { T.a } \\
10^{-2}\end{array}$ & 18.7 & $\begin{array}{l}\text { T.a } \\
10^{-2}\end{array}$ & 15.5 & $\begin{array}{c}\text { T.a } \\
10^{-2}\end{array}$ & 11.2 \\
\hline $\begin{array}{l}\text { A.m } \\
10^{-1}\end{array}$ & 16.7 & $\begin{array}{l}\text { A.m } \\
10^{-1}\end{array}$ & 16.7 & $\begin{array}{l}\text { A.m } \\
10^{-1}\end{array}$ & 11.2 \\
\hline $\begin{array}{c}\text { T.a } \\
10^{-1}\end{array}$ & 17.2 & $\begin{array}{c}\text { T.a } \\
10^{-1}\end{array}$ & 16.5 & $\begin{array}{c}\text { T.a } \\
10^{-1}\end{array}$ & 11 \\
\hline
\end{tabular}

En otra investigación en el año 2001 por Molan, se estudiaron las características antibacteriales de la miel in vitro en diluciones al 10 y $5 \%$ ante el Actinomices pyogenes, Klebsiella, Nocardia sp, Staphylococcus aureus, Streptococcus agalactiae, Streptococcus dysgalactiae y Streptococcus uberis, bacterias causantes de mastitis bovina, los resultados indicaron que las 7 bacterias fueron inhibidas por la acción de la miel de Manuka en una dilución al 10\% y 6 de 7 bacterias en la dilución al 5\%, en comparación con los resultados de la miel monofloral, la cual inhibió las 7 bacterias en la dilución al 10\% pero en la dilución al $5 \%$ solo 2 especies. La diferencia se basa en que los autores consideran que la miel de Manuka posee propiedades antibacteriales no dependientes del peróxido de hidrogeno, como si las tiene la miel monofloral del estudio y en general la mayoría de las mieles. 


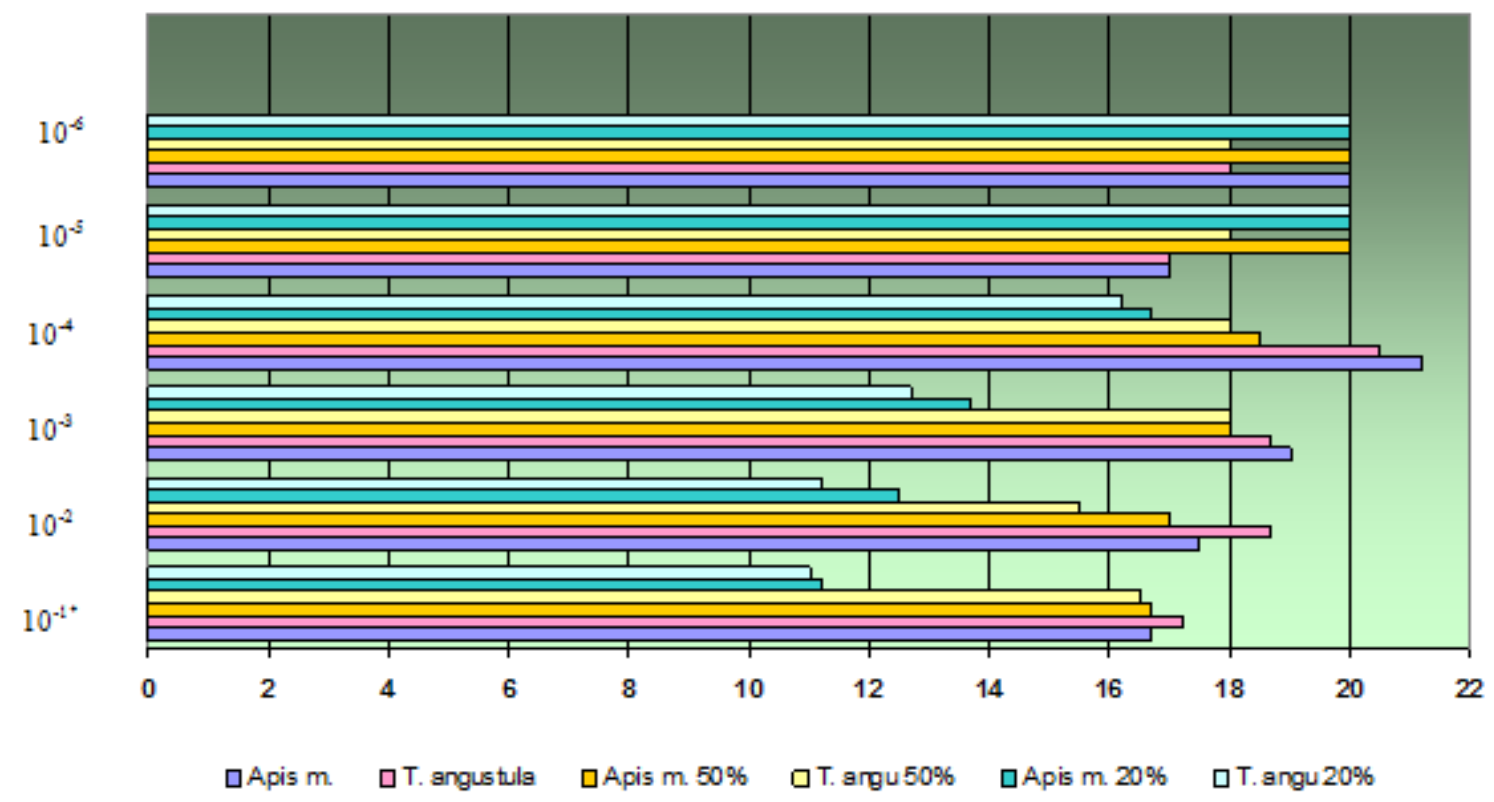

Figura 1. Comparación de la media de los resultados inhibitorios de la miel de Apis mellifera y de Tetragonisca angustula, en sus tres estados puras, diluidas al 50 y $20 \%$. * Concentración de Staphylococcus aureus coagulasa positivo por UFC

A pesar de no haberse obtenido resultados inhibitorios en este ensayo en las diluciones del $20 \%$ ante concentraciones bacteriales altas como lo son $1 \times 10^{-1} \mathrm{y}$ $1 \times 10^{-2}$ (Tabla 1), se debe tener en cuenta que la mayoría de ensayos hechos con los productos de la colmena y específicamente con la miel de abejas, se han realizado a partir de concentraciones bacteriales de $1 \times 10^{-6}$ en adelante; como lo reportó Cabrera et al., en su proyecto de grado en el año 2003, donde el uso de concentraciones superiores a $10^{-6}$ UFC se debe a que se acerca a la concentración bacterial de una herida infectada, lo cual, según Díaz en el 2005, afirma que las heridas in vivo producidas bajo condiciones experimentales demostraron en un modelo biológico que la cantidad relativa de UFC (unidades formadoras de colonias bacteriales) presentes en una herida infecciosa normal, oscila entre las concentraciones de $1 \times 10^{-8}$ y $1 \times 10^{-9}$ UFC. Sin embargo, en este trabajo se utilizó las concentraciones más altas como los son $1 \times 10^{-1}$ hasta $1 \times 10^{-6}$, de las cuales se obtuvieron resultados más favorables de la miel como inhibidor del crecimiento bacteriano del Staphylococcus aureus en comparación con los resultados del antibiótico control. 
En la Tabla 2 se detallan los resultados de las concentraciones mínimas inhibitorias de la miel de la Apis mellifera pura, diluida al 50 y $20 \%(\mathrm{v} / \mathrm{v})$ y de la oxitetraciclina al $10 \%$ (control+). En la Figura 2 se observa que las colonias de Staphylococcus aureus coagulasa positivo fueron sensibles tanto en la miel pura como a la diluida al $50 \%$ de la Apis mellifera para las cuatro concentraciones, pero ante la dilución al $20 \%$ la bacteria mostró resistencia en las concentraciones de $1 \times 10^{-1}$ y $1 \times 10^{-2}$ UFC; no obstante, esta dilución fue medianamente sensible para la bacteria en las concentraciones de $1 \times 10^{-3}$ y $1 \times 10^{-4}$. En todos sus estados la miel fue superior al control positivo: oxitetraciclina al 10\% (Tabla 2, Figura 2).

Tabla 2. Concentraciones Mínimas Inhibitorias de la miel de la abeja Apis mellífera en su estado puro, diluido al 50 y $20 \%$ y de la oxitetraciclina $10 \%$ (control+). Datos expresados como media + error estándar de la media.

\begin{tabular}{ccccc}
\hline Miel pura & $\begin{array}{c}\text { Miel diluida al } \\
\mathbf{5 0 \%}\end{array}$ & $\begin{array}{c}\text { Miel diluida al } \\
\mathbf{2 0 \%}\end{array}$ & $\begin{array}{c}\text { Oxitetraciclina } \\
\mathbf{1 0 \%}\end{array}$ \\
\hline $10^{-1}$ & $16.7+0.4^{\mathrm{b}}$ & $16.7+0.7^{\mathrm{b}}$ & $11.2+0.2^{\mathrm{cde}}$ & $6.5+0.29^{\mathrm{g}}$ \\
& & & & \\
$10^{-2}$ & $17.5+0.2^{\mathrm{b}}$ & $17+0.7^{\mathrm{b}}$ & $12.5+0.2^{\mathrm{cd}}$ & $7.5+0.29^{\mathrm{fg}}$ \\
$10^{-3}$ & $19+0.4^{\mathrm{ab}}$ & $18+0.4^{\mathrm{ab}}$ & $13.7+0.6^{\mathrm{c}}$ & $9.5+0.29^{\mathrm{efg}}$ \\
& & & & \\
$10^{-4}$ & $21.2+0.9^{\mathrm{a}}$ & $18.5+0.6^{\mathrm{ab}}$ & $16.7+0.6^{\mathrm{b}}$ & $10.25+0.25^{\text {def }}$ \\
${ }_{\mathrm{a}, \mathrm{b}, \mathrm{c}, \mathrm{d}}$ Medias con sobrescritos diferentes son estadísticamente diferentes $(\mathrm{P}<0.05)$.
\end{tabular}

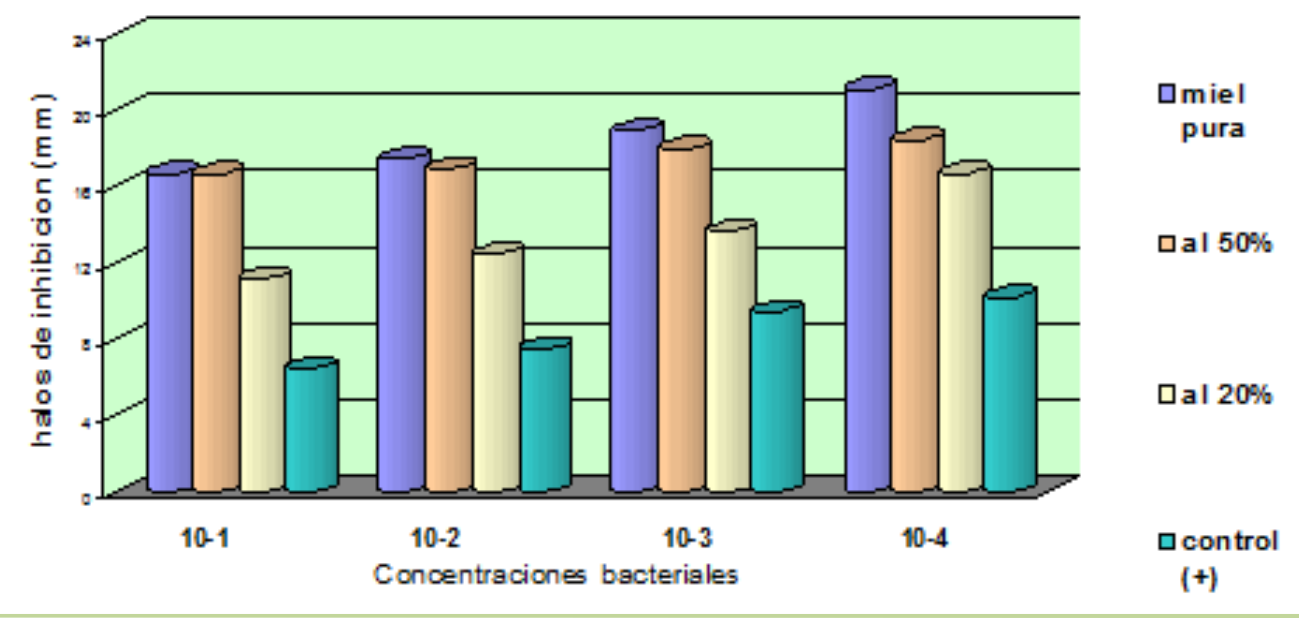

Figura 2. Inhibición del crecimiento bacterial presentado por la miel de la abeja Apis mellifera, pura, diluida al 50 y $20 \%$ y la oxitetraciclina al $10 \%$. 
Estos resultados demuestran y sugieren que la miel pura de la Apis mellifera es más eficaz para las concentraciones bacterianas altas como lo fueron $1 \times 10^{-1}$ hasta $1 \times 10^{-4}$, se sugiere que este efecto se puede dar por que la miel de abejas del género Apis en Colombia contiene un porcentaje mayor de humedad, según estudios de Salamanca en el año 1996, reporta un porcentaje superior al $17.7 \%$ entre el $18.8 \%$ y el $19.5 \%$, para éstas mieles, lo cual se aleja del contenido de humedad estandarizado a nivel mundial, lo que la hace más diluida que la miel comúnmente usada en otros países para diversos experimentos.

Se sugiere que esto podría influir en el resultado debido a que, a pesar de utilizar una muestra pura, su alto contenido de humedad puede activar la oxidación de la glucosa, que se entiende está en mayor cantidad en la presentación pura que en las diluciones al 50 y $20 \%$. Esto se puede comparar con los estudios de Weston en el año 2000, en los cuales propone que la actividad antibacteriana de la miel se debe a la cantidad de glucoxidasa, de catalasa, de peróxido de hidrogeno y de la respuesta enzimática por parte de la bacteria.

Sin embargo, se esperaría observar lo mismo en los resultados de la miel pura de la Apis mellifera y de la Tetragonisca angustula ante concentraciones bacteriales más bajas, como los eran las concentraciones de $1 \times 10^{-5} 1 \times 10^{-6}$, lo cual no se observó; por el contrario, las mieles diluidas de ambas especies fueron las que presentaron mayor inhibición (Tabla 4, Figuras 3 y 4). Este hecho fue observado y registrado por White en el año 1962 en su estudio conocido como: The identification of inhibine, the antibacterial factor in honey, as hydrogen peroxide and its origin in a honey glucose-oxidase system.

La respuesta principal sugerida a esta acción contradictoria, es que la miel sin diluir tiene una osmolaridad mayor a las mieles diluidas, es decir que la alta concentración de azucares afectan el equilibrio intrínseco de la bacteria, así cuando la producción de peróxido es baja o nula en la miel no diluida, esta ejerce su propiedad higroscópica, deshidratando la bacteria. Chirife et al., en el año 1983 basado en sus estudios define que la miel, como otros jarabes de azúcar y gomas saturadas de azúcar, tienen una osmolaridad suficiente para inhibir el crecimiento 
microbiano, pero cuando está es utilizada como capa protectora de la herida, se observa dilución de esta por el exudado de la herida, lo que reduce su osmolaridad a un nivel que deje de controlar la infección.

En otros estudios presentados por Allen et al., en el año 2000 durante el primer Congreso Mundial de la Salud, realizado en Melbourne (Australia), los autores sostienen que durante la Fase 1 de la actividad antibacteriana de la miel ante el $S$. aureus meteciclino resistente (MRSA) presente en heridas causadas por quemaduras; es la osmolaridad la que tiene capacidad de absorción de líquidos. Según estos autores este tipo de actividad antibacteriana está basada en la deshidratación del citoplasma bacteriano que realiza, consiguiendo por un lado la lisis bacteriana y por otro, la incapacidad reproductora de las bacterias no lisiadas. Estas apreciaciones y los resultados observados en el presente trabajo se pueden comparar con las de Gheldof y Engeseth en el año 2002, los cuales reportaron en su estudio que aun cuando las propiedades antimicrobianas de la miel comúnmente son atribuidas a la presencia del peróxido de hidrogeno, estudios con mieles utilizadas en estado puro sin diluir del $100 \% \mathrm{v} / \mathrm{v}$ arrojaron resultados inhibitorios para la mayoría de los cultivos bacterianos, lo que se produce debido probablemente a su alta osmolaridad y acidez, por esta razón, concluyen los autores, la miel cuando es diluida, la producción de peróxido de hidrogeno es el principal agente antimicrobiano ya que ni la osmolaridad ni el pH son suficientes para detener el desarrollo de las bacterias.

Otra razón sugerida según los resultados en el presente trabajo, es que los compuestos de acción antibacterial están en mayor número en la miel pura que en la miel diluida, esto también fue observado por Weston, (2000) el cual dijo que algunos componentes fitoquímicos como los flavonoides y los fenoles, se encuentran en las mieles tanto productores de peróxido de hidrógeno como en las no productoras de peróxido de hidrógeno, tienen ciertas cualidades antibacteriales que influyen en la inhibición.

Igualmente, el Departamento de Agricultura de los Estados Unidos de Norte América en el área de Investigación Agrícola, publica en el 2001, que las mieles 
con mayor cantidad de compuestos antioxidantes potencializan la acción antibacterial, además las mieles de color más intenso contienen una cantidad mayor de carotenos y flavonoides, los cuales tienen propiedades antibacteriales y sumado a esto la presencia de fenoles contribuye a la actividad antimicrobiana de la miel. Esta característica del color la encontramos en la miel de la Apis mellifera (Gráfica 8), por los estudios de los autores mencionados, se sugiere que, en las concentraciones muy altas de bacterias, la miel pura de ambas especies fue superior que los resultados obtenidos en las diluciones; presuntamente debido también por la mayor cantidad de compuestos antioxidantes. Descartamos que se deba al $\mathrm{pH}$, ya que este no es disminuido por la adición del diluyente, por el contrario, se incrementa.

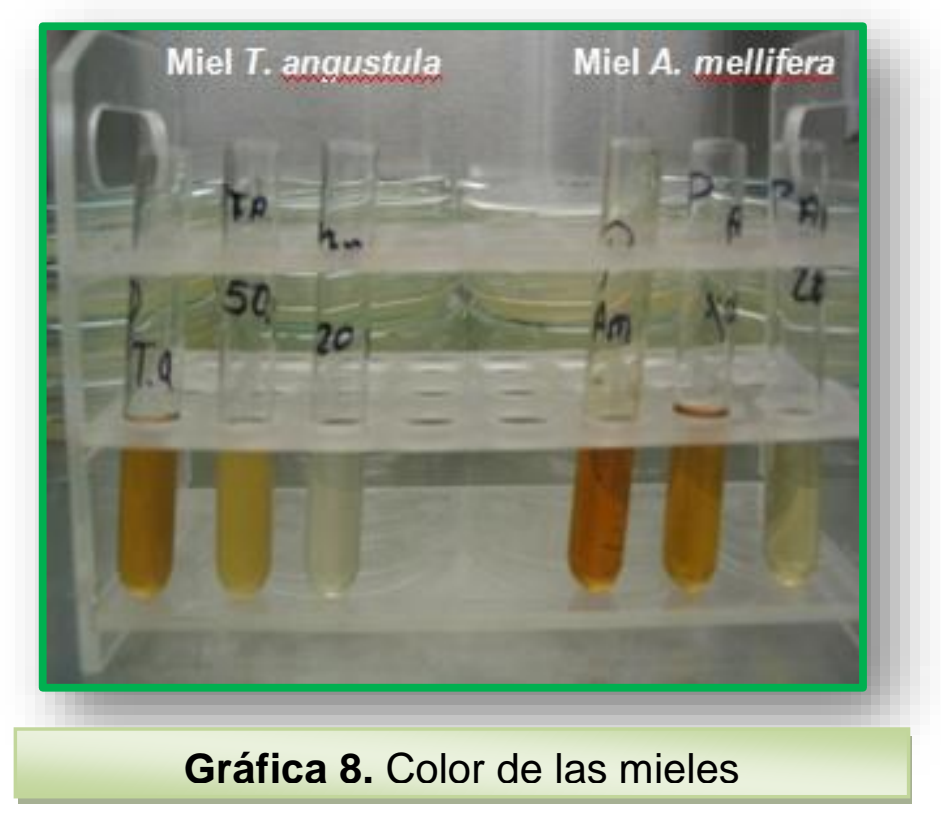

En cuanto a los resultados del antibiótico, la media de la inhibición para la concentración de $1 \times 10^{-4}$ estuvo muy cerca de la obtenida por la miel al $20 \%$, pero la diferencia radica en que la dilución al $20 \%$ se encontraba ante una concentración bacteriana de $1 \times 10^{-2}$, la cual era mayor que la del control, sin embargo, el Staphylococcus aureus coagulasa positivo, mostró resistencia con ambas presentaciones. En la Tabla 3 se detallan los resultados de las concentraciones mínimas inhibitorias de la miel de la Tetragonisca angustula pura, diluida al 50 y $20 \%(\mathrm{v} / \mathrm{v})$. En la Figura 3 se tiene que las concentraciones de 
Staphylococcus aureus coagulasa positivo de $1 \times 10^{-1}$ a $1 \times 10^{-4}$ UFC fueron sensibles a la miel pura de la Tetragonisca angustula, medianamente sensibles en las concentraciones $1 \times 10^{-3}$ y $1 \times 10^{-4}$ UFC ante la dilución al $50 \%$; pero ante la dilución al $20 \%$ de las concentraciones de $1 \times 10^{-1}$ hasta $1 \times 10^{-3}$ UFC fue resistente, solo mostró mediana sensibilidad ante la concentración de $1 \times 10^{-4}$ UFC de dicha dilución (Tabla 3 y Figura 3) (Gráfica 9 y 10).

Tabla 3. Concentraciones mínimas inhibitorias de la miel de la abeja Tetragonisca angustula en su estado puro, diluido al 50 y $20 \%$ y de la oxitetraciclina $10 \%$ (control+). Datos expresados como media \pm error estándar de la media.

\begin{tabular}{ccccc}
\hline Miel pura & $\begin{array}{c}\text { Miel diluida al } \\
\mathbf{5 0 \%}\end{array}$ & $\begin{array}{c}\text { Miel diluida } \\
\text { al } \mathbf{2 0 \%}\end{array}$ & $\begin{array}{c}\text { Oxitetraciclina } \\
\text { al } \mathbf{1 0 \%}\end{array}$ \\
\hline $10^{-1}$ & $17.2 \pm 0.8^{\mathrm{ab}}$ & $16.5 \pm 0.8^{\mathrm{b}}$ & $11 \pm 0.4^{\mathrm{de}}$ & $6.5 \pm 0.29^{\mathrm{g}}$ \\
$10^{-2}$ & $18.7 \pm 0.4^{\mathrm{ab}}$ & $15.5 \pm 0.2^{\mathrm{bc}}$ & $11.2 \pm 0.2^{\mathrm{de}}$ & $7.5 \pm 0.29^{\mathrm{fg}}$ \\
$10^{-3}$ & $18.7 \pm 0.8^{\mathrm{ab}}$ & $18 \pm 0.7^{\mathrm{ab}}$ & $12.7 \pm 1^{\mathrm{cd}}$ & $9.5 \pm 0.29^{\mathrm{efg}}$ \\
$10^{-4}$ & $20.5 \pm 1.1^{\mathrm{a}}$ & $18 \pm 0.4^{\mathrm{ab}}$ & $16.2 \pm 0.4^{\mathrm{b}}$ & $10.25 \pm 0.25^{\text {def }}$ \\
& & & & \\
\hline${ }^{*} \mathrm{a}, \mathrm{b}, \mathrm{c}, \mathrm{d}$ Medias con sobrescritos diferentes son estadísticamente diferentes $(\mathrm{P}<0.05)$.
\end{tabular}

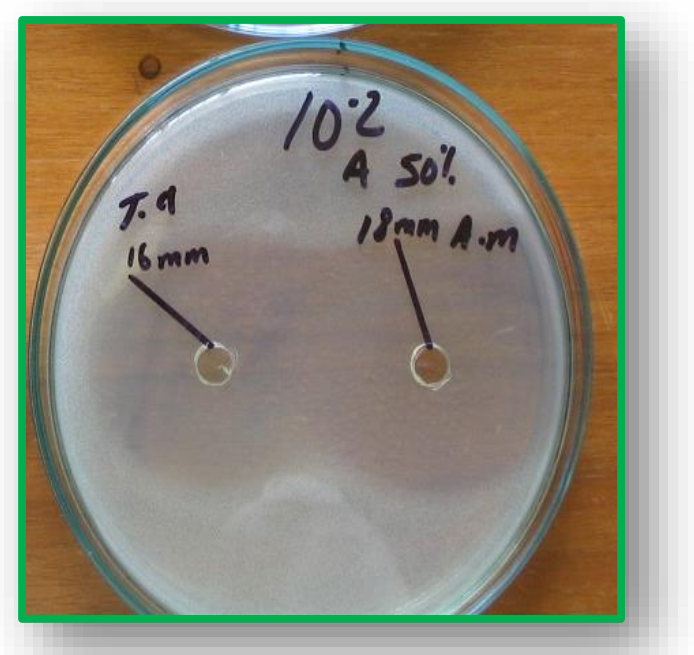

Gráfica 9. Halos de inhibición 2 UFC Mieles diluidas al $50 \%$

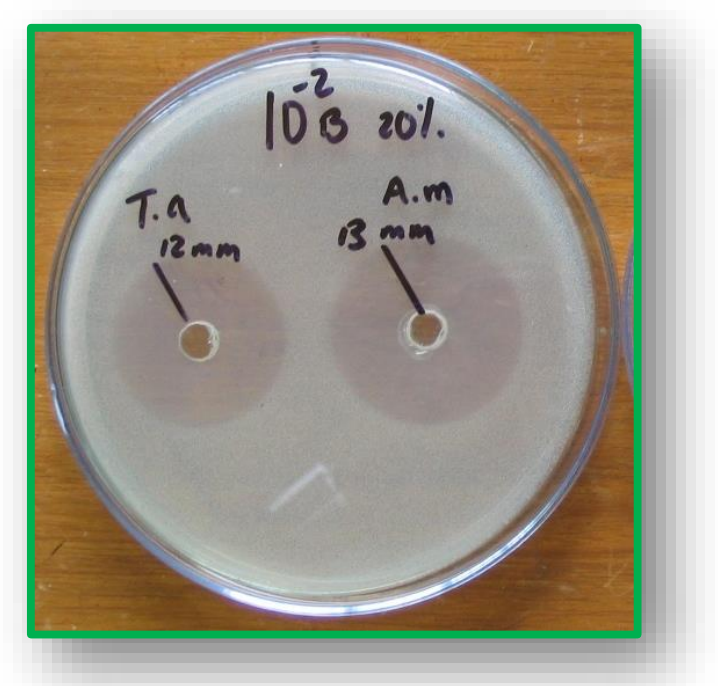

Gráfica 10. Halos de inhibición 10$10^{-2}$ UFC Mieles diluidas al $20 \%$ 
Estos resultados sugieren que la miel de la abeja Tetragonisca angustula logró inhibir el crecimiento de la bacteria gracias a su alto contenido de humedad, superior al de la abeja Apis mellífera, según Nates en el año 1996 establece que la miel de esta especie tiene un contenido de humedad del $25 \%$ y un pH más ácido que el $\mathrm{pH}$ de la miel de la abeja Apis mellífera, pero no fue suficiente para inhibir las altas concentraciones al $20 \%$ de su dilución, sin embargo comparada con los resultados del antibiótico control de las concentraciones $10^{-4}$ y $10^{-3}$, fue superior su actividad aun cuando el Staphylococcus aureus presentó resistencia, el halo de la dilución al $20 \%$ de la miel de esta especie fue mayor a la del control ya que estaba enfrentada a la máxima concentración $1 \times 10^{-1}$ UFC.

Igualmente se puede observar que la miel pura de la Apis mellifera fue eficaz para las concentraciones bacterianas altas como lo fueron $1 \times 10^{-1}$ hasta $1 \times 10^{-4}$, se sugiere que esto se deba a su osmolaridad alta, a diferencia de la miel pura de la Tetragonisca angustula la cual demostró mayor inhibición ante las concentraciones $10^{-2}$ y $10^{-3}$ que la presentada por la miel de la Apis mellifera en su estado puro. Se sugiere que este efecto se puede dar, como consecuencia de que la miel de abejas del género Apis tiene propiedades antibacteriales en su estado puro gracias a su osmolaridad alta, y la miel de la Tetragonisca angustula en las concentraciones bacteriales altas, actúa principalmente gracias a la producción de peróxido de hidrogeno en su estado puro que se encuentra más diluido que en el de la Apis, y en un segundo plano se esperaría que la osmolaridad también refuerce su actividad inhibitoria.

En las concentraciones bacteriales de $1 \times 10^{-5}$ y de $1 \times 10^{-6}$ no se produjo crecimiento bacteriano por lo cual no se obtuvieron resultados inhibitorios, conservándose la miel y los controles intactos dentro de los pozos, sin presencia de colonias contaminantes. Se sugiere que la bacteria no alcanzó un crecimiento exponencial en el tiempo estimado. Sin embargo, en un ensayo realizado posteriormente, basado en la misma metodología se repitieron los cultivos de estas dos concentraciones. En la Tabla 4 se muestran los resultados obtenidos de la segunda prueba realizada a las concentraciones de $1 \times 10^{-5}$ y $1 \times 10^{-6}$ UFC de la miel 
pura, diluida al 50 y al $20 \%$ de las dos clases de mieles, que se realizaron después de no haberse obtenido los resultados esperados.

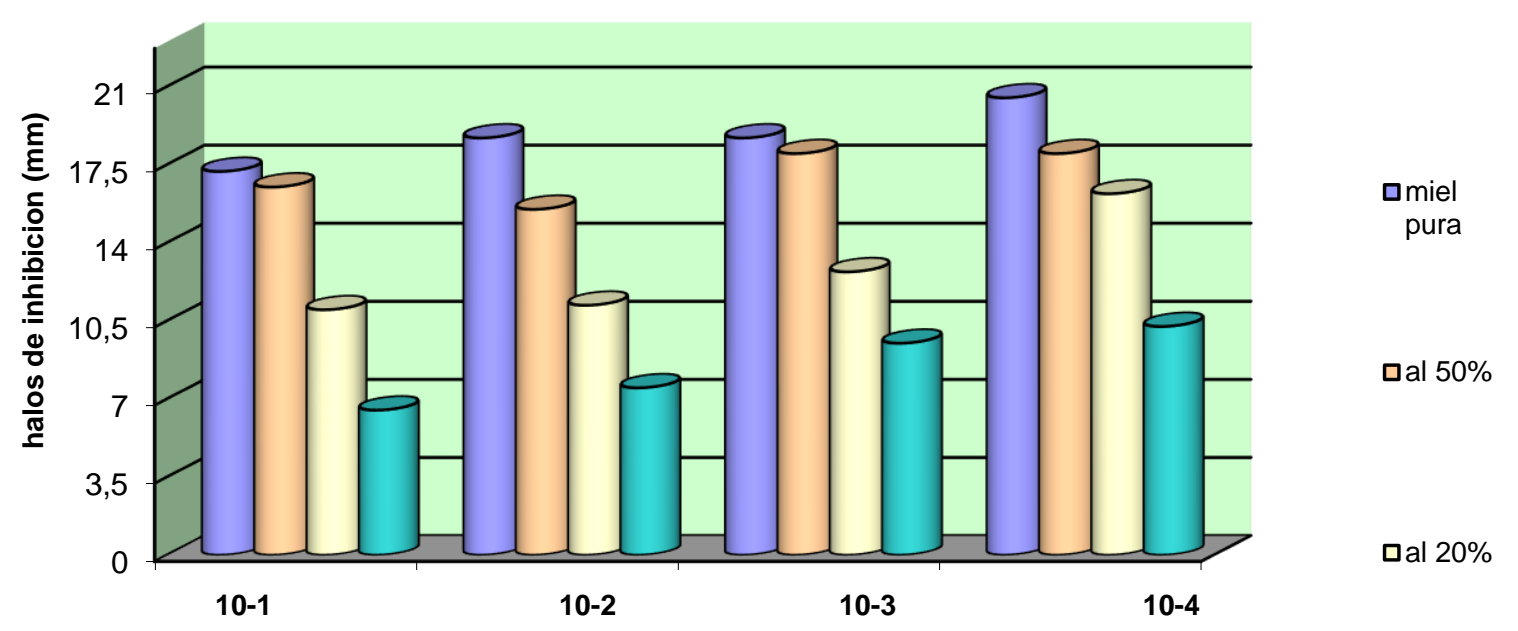

concentraciones bacteriales deStaphylococcus aureus

口control

$(+)$

Figura 3. Inhibición del crecimiento bacterial presentado por la miel de la abeja Tetragonisca angustula pura, diluida al 50 y $20 \%$ y la oxitetraciclina al $10 \%$.

Tabla 4. Concentración mínima inhibitoria de la miel de la Apis mellifera y la miel de la Tetragonisca angustula, puras, diluidas al 50 y $20 \%$ en las concentraciones de $1 \times 10^{-5}$ y $1 \times 10^{-6}$ UFC

\begin{tabular}{|c|c|c|c|c|}
\hline & \multirow{2}{*}{$\begin{array}{c}10^{-5} \text { UFC } \\
\text { Apis } \\
\text { mellifera }\end{array}$} & \multicolumn{3}{|c|}{$10^{-6}$ UFC } \\
\hline & & $\begin{array}{c}T . \\
\text { angustula }\end{array}$ & $\begin{array}{c}\text { Apis } \\
\text { mellifera }\end{array}$ & $\begin{array}{c}T . \\
\text { angustula }\end{array}$ \\
\hline Miel pura & $17 \mathrm{~mm}$ & $17 \mathrm{~mm}$ & $20 \mathrm{~mm}$ & $18 \mathrm{~mm}$ \\
\hline Miel al 50\% & $20 \mathrm{~mm}$ & $18 \mathrm{~mm}$ & $20 \mathrm{~mm}$ & $18 \mathrm{~mm}$ \\
\hline Miel al $20 \%$ & $20 \mathrm{~mm}$ & $20 \mathrm{~mm}$ & $20 \mathrm{~mm}$ & $20 \mathrm{~mm}$ \\
\hline
\end{tabular}


En las Figuras 4 y 5 se observa que el Staphylococcus aureus coagulasa positivo en concentraciones $10^{-5}$ UFC y $10^{-6}$ UFC es sensible a las mieles, tanto de la Apis mellifera como a la de Tetragonisca angustula y comprueba que los halos de mayor diámetro de inhibición, corresponden a las mieles diluidas al 50 y $20 \%$ de ambas clases de mieles respectivamente.

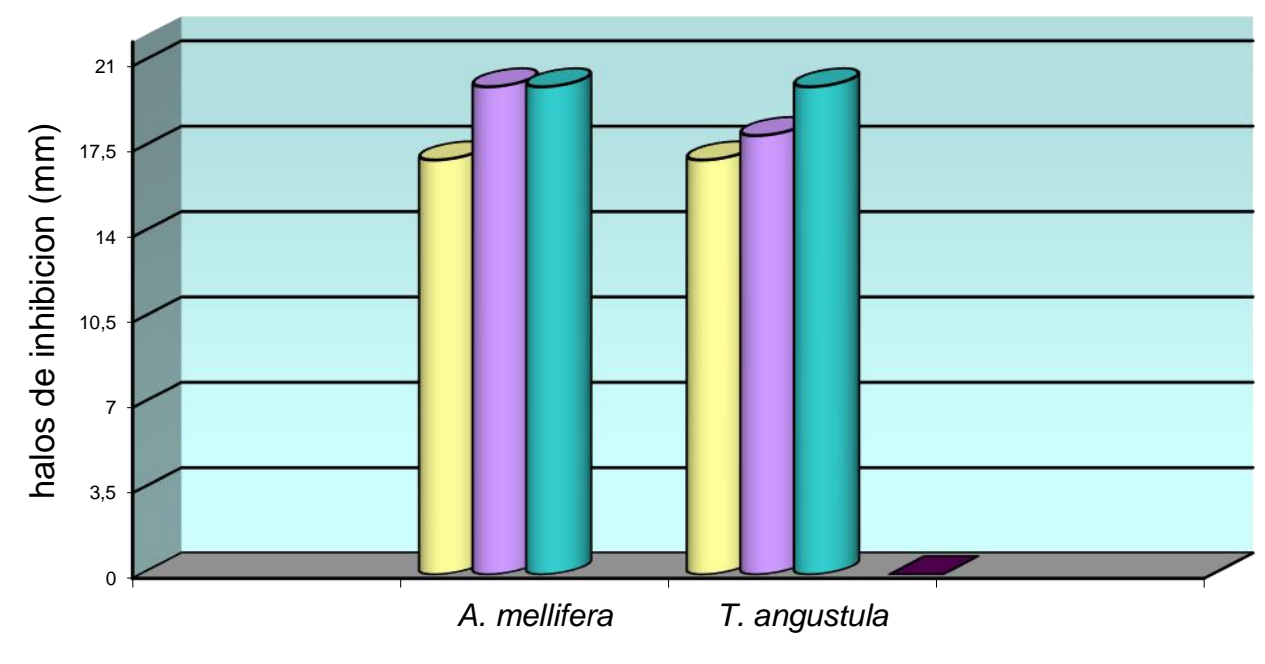

口miel pura

口al $50 \%$

aal $20 \%$

Figura 4. Inhibición del crecimiento bacterial presentado por la miel de la abeja Tetragonisca angustula y la miel de la Apis mellífera puras, diluidas al 50 y $20 \%$ ante la concentración bacterial de $1 \times 10^{-5}$

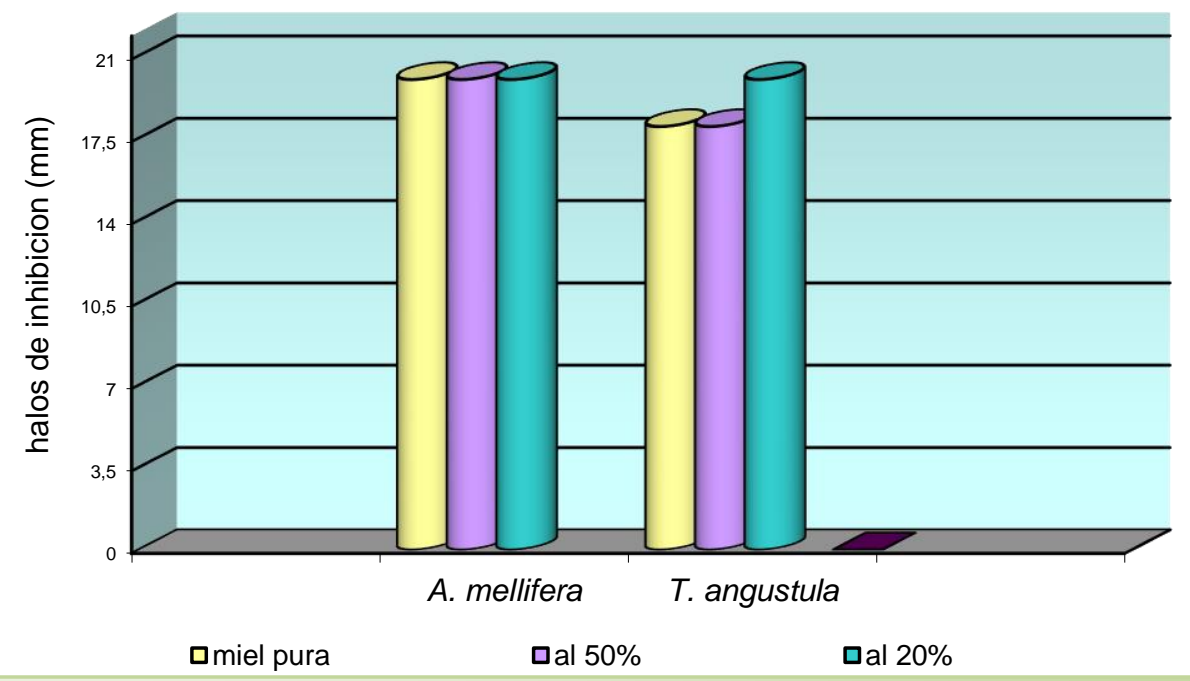

Figura 5. Inhibición del crecimiento bacterial presentado por la miel de la abeja Tetragonisca angustula y la miel de la Apis mellífera, puras, diluidas al 50 y $20 \%$ ante la concentración bacterial de $1 \times 10^{-6}$ 
El diámetro de los halos de la Tetragonisca angustula fue aumentando, sin embargo, ante las menores concentraciones bacteriales a medida que la miel era más diluida, a diferencia de las mieles de la Apis mellifera, las cuales mantuvieron los diámetros de los halos constantes a partir de la dilución al $20 \%$ de la concentración de $1 \times 10^{-5}$ y en todas las pruebas en concentración $1 \times 10^{-6}$. En estos resultados podemos considerar que la miel de abejas tiene un poder inhibitorio más alto en las presentaciones diluidas que en las presentaciones puras, debido a la mayor producción de peróxido de hidrogeno y a la formación de ácido glucónico derivado de la reacción de la glucosa con el agua, por la acción de la glocoxidasa.

Pruitt y Reiteir en el año 1985, observaron y comunicaron que después de varios estudios está claro que el nivel de peróxido de hidrógeno en la miel es muy bajo, pero que sigue siendo eficaz como agente antimicrobiano y es más eficaz cuando es provisto por la acción continua de la glucoxidasa a diferencia de la presentación aislada usado en los tratamientos clínicos. Efem en 1988, recomendó la aplicación de miel en el tratamiento de ulceras, lesiones herpéticas, grietas y llagas; después del ensayo con 50 pacientes que presentaban ulceraciones de piel, todos fueron tratados con miel de abejas de los cuales el $70 \%$ sano completamente, el $22 \%$ sanaron parcialmente y un $8 \%$ no mostró mejoría alguna. Refiere el autor que, debido a sus múltiples propiedades como la hiperosmolaridad, la producción de peróxido de hidrogeno y $\mathrm{pH}$ ácido, la hacen un agente antimicrobiano natural de origen animal. Molan en el año 1992 explica que la actividad antibacteriana de la miel natural, es debido a las enzimas como la glucoxidasa, que es adicionada a la miel por las abejas y que regula la cantidad de peróxido de hidrógeno, cuyo efecto es reconocido como antibacteriano.

Weston en al año 2000 después de sus ensayos basados en las diferentes cantidades de catalasa en la miel hace referencia que la principal actividad antibacteriana se debe a la producción de peróxido de hidrogeno, y que pueden haber compuestos fitoquímicos que colaboren con esta, pero no son específicos para todas las clases de mieles. 
En el año 2003 Williams y Maureen, refieren que después de realizar estudios para determinar las cualidades antibacteriales de la miel de abejas en tratamientos impartidos a pacientes con heridas por quemadura, establece que un número de características inherentes a la miel pudieron contribuir a su capacidad de luchar contra dichas infecciones y de promover la curación y cicatrización, aclara que un alto contenido de los azúcares permite que la infección y el líquido exudado por las heridas disminuyan por un proceso llamado ósmosis, a la vez la miel previene el crecimiento bacteriano con su $\mathrm{pH}$ ácido y por una enzima del grupo de las oxidasas, que induce a la producción de pequeñas cantidades de peróxido de hidrógeno, concluye que un número considerable de estudios, han confirmado los efectos antibacterianos de la miel en ensayos de prueba, sin embargo hay que tener en cuenta que así como hay diversas mieles también hay diversos niveles de la actividad contra bacterias específicas.

Bangroo et al., en el año 2005 compararon en un estudio con pacientes del pabellón de quemados del área de pediatría, la eficacia de la miel y la sulfadiazina de plata; los mejores resultados obtenidos fueron en los que se utilizó la miel de abejas, refiriendo que esta actividad antibacteriana se debida a los inhibidores presentes en miel, principalmente el peróxido de hidrógeno. Lo que está acorde con los resultados obtenidos en otros estudios publicados, que concuerdan en que la acción inhibitoria del crecimiento microbiano de las mieles, se debe a la presencia de peróxido de hidrogeno en las mieles diluidas (Allen y Molan, 2002; Bose, 1982; Cabrera et al., 2002; Cooper y Molan, 1999; Efem, 1988; Molan, 1992; Ortiz, 1990; Salazar, 2001; Weston, 2000). Como se aprecia en la Tabla 5 y la Figura 6, la miel de la Tetragonisca angustula tiene un pH más ácido que el de la miel de la Apis mellífera, lo cual sugiere que su $\mathrm{pH}$ ácido favoreció al efecto inhibitorio en concentraciones bacteriales superiores a $1 \times 10^{-3}$, lo cual concuerda con estudios de otros autores los cuales se basan en que la acidez de la miel es inapropiada para que se desarrollen las bacterias debido a la desactivación de las enzimas bacterianas por causa de ésta. 
Tabla 5. Comparación de los resultados del pH presentado por Miel de la abeja Apis mellífera y la miel de la abeja Tetragonisca angustula en estado puro y diluido al 50 y $20 \%$.

\begin{tabular}{ccc}
\hline Miel & Apis mellifera & Tetragonisca angustula \\
\hline Pura & $\mathrm{pH} 4.0$ & $\mathrm{pH} 3.5$ \\
Diluida al $50 \%$ & $\mathrm{pH} 4.5$ & $\mathrm{pH} 4.0$ \\
Diluida al $20 \%$ & $\mathrm{pH} 5.0$ & $\mathrm{pH} 4.5$ \\
\hline
\end{tabular}

Nates, (1996) sostiene que las mieles de los meliponios tienen una actividad antibacteriana que va desde 2.50 (mediana) hasta 4.94 (máxima) en una escala de cinco, menor que la presentada por la miel de la Apis mellifera, lo que está acorde con los resultados inhibitorios de la miel de la Tetragonisca angustula presentados en este ensayo ya que en las concentraciones inferiores a $1 \times 10^{-3} \mathrm{ni}$ el peróxido de hidrógeno, ni la osmolaridad, ni la acidez, lograron producir un efecto significativo ante un número tan elevado de colonias.

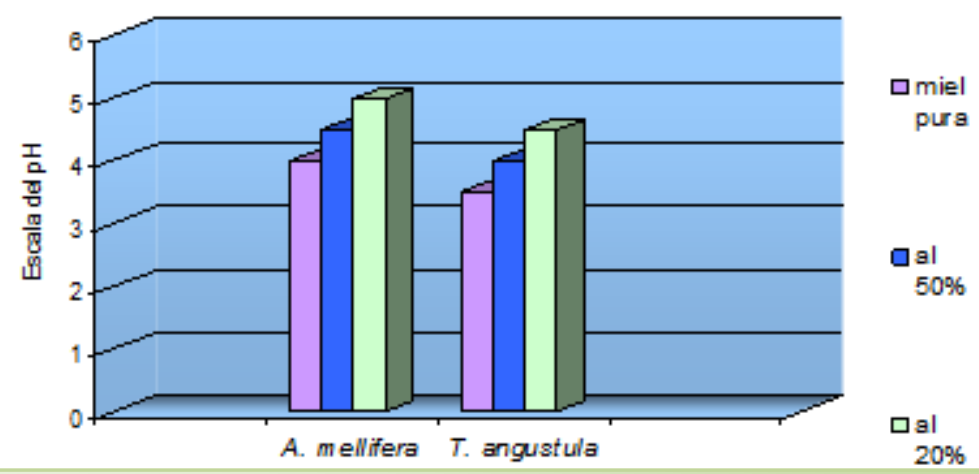

Figura 6. Gráfica comparativa de los resultados del pH presentado por Miel de la abeja Apis mellífera y la miel de la abeja Tetragonisca angustula en estado puro, diluido al 50 y $20 \%$.

Cisneros et al., (1997) en sus estudios sostiene que es el cambio brusco en el pH lo que produce una alteración en la concentraciones de protones y por ende la alteración de las estructuras de la enzima bacteriana, inactivando sus propiedades catalíticas, lo cual si se observó en nuestro ensayo en las concentraciones de $10^{-5}$ y $10^{-6}$ ante las diluciones de ambas mieles al 50 y $20 \%$; este $\mathrm{pH}$ también se vio 
involucrado en la actividad antibacterial gracias a la formación de ácido glucónico resultante de la acción de la glucoxidasa, es decir que a medida que se diluía la miel, la glucoxidasa reaccionaba con la glucosa, obteniéndose de esta reacción: peróxido de hidrogeno y ácido glucónico (Tabla 5 y Figura 6).

\section{CONCLUSIONES}

Se comprobó durante este estudio que la miel de la abeja Apis mellífera y de la Tetragonisca angustula, puras y diluidas al 50 y $20 \%$, poseen propiedades antibacteriales que las hacen efectivas para detener el crecimiento de las colonias del Staphylococcus aureus coagulasa positivo, en un ensayo in vitro y que las concentraciones mínimas inhibitorias de la miel dependen de la concentración bacteriana y del estado puro o diluido de las mismas mieles.

Los compuestos de la miel y sus características como la acidez y la hiperosmolaridad, hacen de esta sustancia una alternativa para inhibir el crecimiento bacterial, como en este caso el del Staphylococcus aureus coagulasa positivo, por lo que se podría considerar a la miel como un agente antimicrobiano natural de origen animal.

La miel de la Tetragonisca angustula que se encuentra más diluida que la miel de la abeja común es una buena alternativa antimicrobiana por la mayor producción de peróxido de hidrógeno y mayor acidez; comparada con la miel de Apis mellífera.

Es fundamental tener en cuenta que las propiedades antibacteriales de la miel difieren debido a los múltiples tipos de néctar que existen, de la población de abejas en el momento de la recolecta, de la secreción de glucoxidasa por parte de las abejas pecoreadoras, y fundamentalmente que la miel de estudio, debe ser miel cruda, es decir sin sufrir ningún tipo de tratamiento con calor, debido a la destrucción de enzimas por la acción de este. Es recomendable en casos de que se requiera una muestra estéril de cualquier microorganismo, hacerlo por el método de irradiación, el cual no desnaturaliza los compuestos presentes en la miel. 
Con una población bacteriana estimada en los procesos infecciosos, a partir de $1 \times 10^{-8}$ UFC se sugeriría hacer un ensayo in vivo para comprarlo con los resultados in vitro obtenidos en el presente trabajo.

Teniendo en cuenta la conclusión de los resultados, se podría recomendar que para próximos estudios de esta índole, es necesario establecer antes, la presencia y cantidad de las enzimas catalasa y glucoxidasa en la miel sometida a estudio; además de obtener el porcentaje de humedad específico para la misma.

\section{REFERENCIAS BIBLIOGRÁFICAS}

1. Al-Jabri A. A., Al-Hosni S. A., Nzeako B. C., Al-Mahrooqi Z. H., Nsanze H. Antibacterial activity of Omani honey alone and in combination with gentamicin. Laboratories of the Department of Microbiology and Immunology, College of Medicine and Health Sciences, Sultan Qaboos University, Sultanate of Oman in 2004.

2. Allen, K. L., Molan, P. C. The sensitivity of mastitis causing bacterias to the antibacterial activity of honey. Hamilton, New Zealand: s. n. 2002.

3. Allen K. L., Hutchinson G., Molan P. C. The potential for using honey to treat wounds infected with MRSA and VRE. First World World Healing Congress; Melbourne, Australia. 2000.

4. Allen, K. L., Molan, P. C., Reid, G. Survey of activity of some New Zealand honeys. New Zealand: Apypharm. 1991.

5. Asis M. para todos editado en tìa trini, S.A. México, 355 p. 2007.

6. Bangroo A. K., Ramji K., Smita C. Honey dressing in pediatric burns. Journal of the Indian Association Pediatric Surgeons;10 (2):172-5. 2005

7. Bose, B. Honey or sugar in treatment of infected wounds. s. I.: s. n., 1982.

8. Cabrera, L. et al. Actividad antibacteriana de la miel de abejas multiflorales (Apis mellifera scutellata) de cuatro zonas apícolas del estado Zulia de Venezuela. Caracas (Venezuela): Universidad de Caracas, Laboratorio de alimentos, Facultad de Ciencias, 2002.

9. COMISION EUROPEA AL PARLAMENTO Y CONSEJO. Plan de acción contra la amenaza creciente de las resistencias bacterianas. Comunicación 748 final, 17 p. Bruselas, 2011.

10. Chirife J., Herszage L., Joseph A., Kohn E.S. In vitro study of bacterial growth inhibition in concentrated sugar solutions: microbiological basis for the use of sugar in treating infected wounds. Antimicrob Agents Chemother; 23 (5): 76673. 1983

11. Cisneros, E.; Pupo, J.; Céspedes, E. Enzimas que participan como barreras fisiológicas para erradicar los radicales libres: III Glutation peroxidasa. En: Revista Cubana de Investigaciones Biomédicas. 16 (1): 10-15. 1997. 
12. Cooper, R. A.; Molan, P. C.; Harding, K. G. Antibacterial activity of honey against strain of Staphylococcus aureus from infected wound. En: Society medical. 1999.

13. Crane, E. A book of Honey. Estados Unidos: Oxford University, 1980.

14. Crane, E., Graham, J. Bee hives of the ancient world. En: Chapter No. 66. Hamilton (Illinois): Dadant, 1985. p. 148-170.

15. Díaz, S. L. Modelo de herida infectada. Instituto Superior de Medicina Militar. En: Cubana de Medicina. La Habana 2005.

16. Efem, S. E. Clinical observations on the wound healing properties of honey. S. I:, s. n., 1988.

17. Engel, M. Fossil honey bees and evolution in the genus Apis (Hymenoptera: Apidae). Apidologie. En: Chapter Nos. 29-30. p. 265-281. 1998.

18. García R., J. A.; Canton, R. Anton, R., García, S. E. Métodos básicos para el estudio de la sensibilidad a los antimicrobianos. En: Acta Médica (Chile). 2000.

19. Gheldof N., Engeseth N. Antioxidant capacity of honey from various floral sources based on the determination of oxygen radical absorbance capacity and inhibition of in vitro lipoprotein oxidation in human serum samples. J Agric Food Chem.; 50: 3050-3055. 2002

20. Molan, P. C. The antibacterial activity of honey. The nature of antibacterial activity. Bee world. 1992.

21. Molan, P. C. Potential of honey in the treatment of wounds and burns. s. I.: s. n., 2001.

22. Molan, P. C., Russel, K. M. Non-peroxide antibacterial activity in some New Zealand honeys. New Zealand: s. I: s. n., 1988.

23. NATIONAL HONEY BOARD. pH Acids in Honey. (The National Honey Board, 390 Lashley Street Longmont,CO 80501-6045 USA).

24. Nates, P. G. Abejas sin aguijón de Colombia ( $H$. melliponini). Bogotá: Academia Colombiana de Ciencias Exactas, Físicas y Naturales, C. E Javeriano, 1996.

25. Ortiz, V. A. Actividad germicida de la miel (Factores). Castilla: Laboratorio de la Miel, Centro Apícola de Castilla, 1990.

26. Pruitt, K. M., Reiter, B. Biochemistry of perioxidasa system (antimicrobial effects). New York: s. n., 1985.

27. PROFECO. Calidad de miel de abeja, Revista del Consumidor No. 287, Enero 2001. 5 p. [consultado 22 de febrero 2013] Disponible En: http://www.profeco.gob.mx/revista/pdf/est 01/miel.pdf

28. Salazar, L. A. Actividad antimicrobiana in vitro de la miel de abejas sobre bacterias cariogénicas (Streptococcus mutans). Chile: Universidad de La Frontera, Ciencias básicas de la Facultad de Medicina, 2001.

29. Salamanca, G. Elementos para la interpretación de la Apicultura en Colombia. Universidad del Tolima, Facultad de Ciencias, Departamento de Química, 1996.

30. Turner, F. J. Hydrogen peroxide and other oxidant disinfectants. 3 ed. Philadelphia: s. n., 1983.

31. Ulloa J., Mondragón P., Rodríguez R. y Reséndiz J. La miel de abeja y su importancia. Revista Fuente Año 2, No. 4, Septiembre 2010:11-18 
32. Wayne, W. D. Bioestadística, base para el análisis de las ciencias de la salud. 3 ed. México: Limusa, 2000.

33. Weston, R. J. The contribution of catalase and other natural products to the antibacterial activity of honey: a review. Food Chemistry. s. I: s. n., p. 235-239. 2000.

34. White, J. W. Composition of American Honey. Washington: Department of Agriculture, 1962.

35. Williams, N. D. The topical use of the honey is beneficial in the treatment of wounded and he/she burns, according to a critic in the newspaper of the wound, of Ostomy, and of the occupation of nurse of Continence (2002; 29:295-300). Publication Health notes Newswire. 2003. 